\title{
LA TUTELA IMPERIAL DE LOS INDÍGENAS EN EL SEGUNDO IMPERIO MEXICANO (1864-1866)
}

\author{
JESÚS FRANCISCO RAMÍREZ BAÑUELOS
}

Iteso, México

\begin{abstract}
Resumen: Este trabajo estudia la estrategia de orden social imperial de protección tutelar a los indígenas en el Segundo Imperio Mexicano. Se pretende documentar cómo el emperador Maximiliano actuó para proteger a los indígenas clasificándolos legalmente como clases menesterosas, así como para resolver los conflictos de los pueblos indígenas entre sí y entre pueblos indígenas y particulares en un sistema similar al que prevaleció en la Nueva España.
\end{abstract}

Palabras clave: Maximiliano, indígenas, tutela, clases menesterosas.

Abstract: This paper studies the imperial social order strategy of tutelary protection of the indigenous people in the Second Mexican Empire. It aims to document how Emperor Maximilian acted to protect the indigenous people by legally classifying them as needy classes, as well as to resolve the conflicts of indigenous peoples among themselves and between indigenous peoples and private individuals in a system similar to the one that prevailed in New Spain.

Keywords: Maximilian, Indigenous, Guardianship, Needy Classes.

\section{Introducción}

Para la viabilidad del Segundo Imperio Mexicano los pueblos indígenas tuvieron una importancia fundamental (Pani, 1998). El interés del emperador por abordar los problemas de los pueblos indígenas se debe no sólo al hecho de que constituían la mayoría demográfica del país (Ratz, 1998: 232) sino sobre todo al reconocimiento de las condiciones de pobreza y aislamiento social en las que se encontraban. El emperador Maximiliano legisló ampliamente durante su gobierno en México abarcando prácticamente todos los ámbitos tanto públicos como privados. Durante el Segundo Imperio Mexicano, la estrategia de orden social imperial tenía por objeto abordar los problemas de integración social de los pueblos indígenas en la sociedad mexicana ordenándolos de acuerdo con los objetivos del imperio de Maximiliano.

El propósito de esta contribución será documentar cómo el emperador Maximiliano publicó algunas leyes para asegurar la protección de los pueblos indígenas con el fin de integrarlos gradualmente a la sociedad mexicana. Explicamos cómo el emperador Maximiliano publicó algunas leyes con contenido tutelar para proteger a los pueblos indígenas en un orden social doméstico similar al 
que existía en la Nueva España (Ramírez Bañuelos, 2020) en el que los pueblos indígenas eran sujetos de protección como parte de una categoría jurídica particular, a saber, las clases menesterosas. Nos acercamos a la investigación a partir de textos normativos, incluyendo leyes, decretos, proclamaciones y circulares ordenadas por el propio emperador o por su gobierno. Los documentos en cuestión fueron compilados por Miguel León Portilla (2003b) en una versión facsímil en la que los textos legales en náhuatl y español pueden verse a dos columnas. Sin embargo, la incidencia del uso de la lengua náhuatl en la eficacia del derecho escapa a los objetivos de esta investigación. Este trabajo se limita al período comprendido entre el 10 de abril de 1864 y el 16 de septiembre de 1866. La primera fecha corresponde al día en que Maximiliano aceptó el trono mexicano y que, para nuestros propósitos, fue también la primera fecha en que se publicó una ley imperial que impacta a la relación con los indígenas, aunque firmada por Félix Eloin (Duchesne, 1968) como jefe del gobierno provisional. La segunda fecha corresponde a la publicación de la última disposición del emperador que pretendía influir en la vida de los indígenas, aunque su gobierno duró hasta el 19 de junio de 1867 cuando fue asesinado en Querétaro.

Para llevar a cabo nuestra investigación, utilizamos el modelo doctrinal de las tres dimensiones del poder del príncipe en la cultura del Ius Commune para comprender las prácticas y el ejercicio del poder del emperador Maximiliano en su imperio. Estas dimensiones de poder son, en primer lugar, la del emperador como titular del poder paterno en una organización familiar (oeconomica), que cubre el espacio público para proteger a los indígenas; en segundo lugar, la del emperador como titular del poder absoluto (solutio legibus), sin reconocer a ningún superior en el espacio territorial de su imperio; y en tercer lugar, la del titular del poder jurisdiccional (iurisdictio), ligada a su función de hacer justicia mediante el dictado de leyes (Vallejo, 2012: 141-178).

\section{La oeconomica y la clasificación de los pueblos indígenas como clases menesterosas}

El Segundo Imperio Mexicano publicó algunas leyes en lengua náhuatl para gobernar a los pueblos indígenas en un orden social doméstico similar a como sucedió en el periodo colonial. El objetivo de la publicación de leyes de contenido doméstico en el Segundo Imperio Mexicano fue incluir a los indígenas en su proyecto imperial protegiéndolos como sujetos bajo la tutela imperial. Durante el Segundo Imperio Mexicano, el emperador actuó como un padre protector de los indígenas (Jancsó, 2009). El emperador Maximiliano se idealizó a sí mismo como la continuación del Huei Tlabtoani - el líder político precolombino de los indígenas(León Portilla, 2003a). Esta posición implicaba dar a los pueblos indígenas la protección paterna a la que estaban acostumbrados durante la etapa colonial. 
Por su parte, los indígenas vieron en el emperador Maximiliano una figura paterna protectora que garantizaba su supervivencia. Así se advierte con claridad en la cita que hace Daniela Marino (2006) de una carta de los vecinos de la aldea de Santa María de Ayotzingo dirigida al emperador Maximiliano, fechada el 18 de junio de 1865 , cuyo texto reza así:

\section{[...] en el nombre de S.M. y de Nuestra Princesa, que Dios nuestro Señor los guarde por muchos años para proteger a los pobres indios indefensos como nosotros, y que ahora que Dios nos ha dado a nuestro padre, lleguemos a tomarnos bajo las alas de su protección y la sombra de S.S. las Islas Magdalenas Imperiales.}

Esta dimensión de la protección paterna se articulaba en torno a una categoría jurídica propia, la de las clases menesterosas. Las clases menesterosas eran el dominio legal donde el emperador actuaba como un padre protector de los indígenas. El emperador Maximiliano empleó un modelo de organización social doméstica similar al que había estado vigente durante la etapa del virreinato de la Nueva España bajo la clasificación de los indígenas como personas miserables (Dios Dios; Busaall, 2014: 153; Ramírez Bañuelos, 2020: 352-359).

Durante la etapa del virreintato de la Nueva España, la noción del padre rey estaba ligada a la difusión del catolicismo (Clavero, 2007). La categorización de los indígenas como "gente miserable" se debió al abogado y asesor indio Gregorio López (Busaall, 2014: 153). Al respecto, el abogado Juan Solórzano Pereyra en su libro Política Indiana publicado en 1646 refiere este tratamiento para los indígenas, señalando que basta con que se conviertan a la fe cristiana para ser protegidos por los castellanos (Solórzano, 1703: 119). La clasificación de los indígenas como "personas miserables" se encuentra en las ordenanzas de Felipe II de las Audiencias de 1565 y Longuisana del 21 de abril de 1580 y de Felipe IV dada en Madrid el 26 de septiembre de 1655, todas ellas compiladas como 4.10 .3 en la Nueva Recopilación; así como en la orden de Felipe III dada en San Lorenzo el 20 de marzo de 1596 y registrada en la Nueva Recopilación con el número 3.14; en las órdenes de Felipe III emitidas en Madrid el $1^{\circ}$ de noviembre de 1607 y San Lorenzo el 24 de abril de 1618 y registradas en la Nueva Recopilación con el número 3.14.5; y en la ordenanza de Felipe III dada a Aranjuez el 26 de mayo de 1609 y registrada en la Nueva Recopilación con el número 6.13.48 (Recopilación de Leyes, 1841).

Por otra parte, la calificación de las "personas miserables" era un criterio de evaluación que el juez debía respetar para resolver casos específicos que le eran sometidos a su jurisdicción que implicaba un privilegio jurisdiccional. Este privilegio consta en la orden de Felipe II emitida en Madrid el 9 de abril de 1591 y registrada en la Nueva Recopilación con el número 3.3.65 (Recopilación de Leyes, 
La tutela imperial de los indígenas en el Segundo Imperio Mexicano (1864-1866)

1841). Así, la República de Indios, derivada de la Política Indiana de Juan Solórzano Pereyra (1646) y la Recopilación de Leyes de los Reyes de las Indias (1681), se consolidó como un espacio territorial específico de los pueblos indígenas. De hecho, era un espacio que había que proteger porque sus miembros eran considerados como hombres débiles expuestos a los abusos y la codicia de los castellanos.

El emperador Maximiliano retomó los aspectos esenciales de esa política tutelar colonial castellana y protegió a los indígenas colocándolos en la categoría legal de menesterosos. Las clases menesterosas eran aquellas personas que, por su pobreza, habían sido relegadas de las actividades públicas y mantenidas aisladas en sus comunidades indígenas. Para proteger a los indígenas, el emperador Maximiliano actuó ex certa sciencia como se puede ver en el preámbulo del decreto de creación de la Junta Protectora de las Clases Menesterosas, que señala:

\begin{abstract}
Considerando que desde que aceptamos el trono de México, al que hemos sido llamados por la voluntad del pueblo, las clases necesitadas siempre han sido objeto de nuestra especial petición; y considerando que en nuestro viaje hacia el interior del Imperio hemos podido conocer las necesidades y sufrimientos de los que han sido víctimas hasta el día de hoy: mejorar lo más eficazmente posible la condición de esta desafortunada clase (León Portilla, 2003b: 28).
\end{abstract}

Faustino Galicia Chimalpopoca, asesor indígena de Maximiliano, también expresó este pleno conocimiento por parte del Emperador de las condiciones de vida de los indígenas, al afirmar que: “[...] Afortunadamente, nuestro ilustre soberano lo sabe todo, porque vio y entendió su causa mejor que nadie, visitando ciudades, pueblos y barrios sin descanso, lo presenció de una manera tangible" (Marino, 2006).

\title{
2.1. E1 derecho de las clases menesterosas a ser escuchadas personalmente por el emperador
}

El emperador Maximiliano comprendió que un elemento primordial para poder proteger a las clases menesterosas era establecer las condiciones para escuchar sus necesidades y problemáticas (Maximiliano, 1869). El derecho a ser escuchado por el emperador estaba garantizado a todos los mexicanos por el artículo 8 del Estatuto Provisional del Imperio Mexicano. Además, el Reglamento de Audiencias publicado el 10 de abril de 1864 estableció la forma en que los habitantes del Imperio ejercían su derecho a ser escuchados, a saber, todos los domingos en audiencia pública (León Portilla, 2003b: 27). El Reglamento de Audiencias fue una medida legal por la 
cual el emperador Maximiliano actuó como protector paterno al escuchar personalmente las peticiones y quejas de los indígenas. Aunque las normas de las audiencias no estaban dirigidas específicamente a los pueblos indígenas, observamos que el procedimiento era informal, lo que lo hacía accesible a los pueblos indígenas. El procedimiento consistía en inscribirse en la oficina del gobierno con cuarenta y ocho horas de anticipación, o incluso menos si el asunto era urgente.

La realización de audiencias públicas, o si el peticionario lo solicitaba en secreto, fue una actividad en la que el emperador ejerció su poder en un modelo que tiene similitudes con la función del virrey en la audiencia de la Ciudad de México durante la Nueva España (Ordenanzas Reales de Castilla, 1484). Apreciamos también la diferencia en las condiciones para el ejercicio del derecho de petición vigente en los territorios que no estaban bajo control imperial sino del presidente liberal Benito Juárez, quien exigió su formulación escrita (Constitución de 1857, artículo 8).

Como podemos ver, el derecho a ser escuchado, incluyendo el derecho de petición, protegido por el emperador Maximiliano era mucho más flexible que el formalismo escrito establecido por el régimen liberal del presidente Juárez. Esto se debe a que el emperador utilizó este derecho como medio de protección para los indígenas que, en la mayoría de los casos, no sabían leer ni escribir.

\subsubsection{La Junta Protectora de las Clases Menesterosas}

Además de las audiencias personales semanales, el emperador creó una institución específica para recibir peticiones y quejas de las clases menesterosas. Esta institución fue la Junta Protectora de las Clases Menesterosas.

El artículo 4 del decreto de 10 de abril de 1865 por el que se crea la Junta Protectora de las Clases Menesterosas establece como sus atribuciones, entre otras, las siguientes: “[...] I. Dictaminar sobre los casos que se le sometan para consulta; II. Proponer las medidas que estime oportunas para mejorar la situación moral y material de las clases necesitadas [...]" (León Portilla, 2003b). Como se advierte, la Junta Protectora de las Clases Menesterosas era una herramienta fundamental de la que se valía el emperador para proteger a sus súbditos.

La Junta Protectora de las Clases Menesterosas tenía una función consultiva y no de toma de decisiones. Sus opiniones fueron dirigidas a la atención del emperador para que tomara una decisión. La Junta Protectora de las Clases Menesterosas podía solicitar un informe a las autoridades municipales o departamentales competentes $y$, a continuación, emitir un dictamen que se transmitía al Ministerio del Interior para su comunicación al Consejo de Ministros y su presentación al emperador. Por su función consultiva, la Junta Protectora de las Clases Menesterosas nos recuerda al Consejo de Indias (Ministerio de Cultura y Deporte, 07-05-2019) durante el dominio castellano en la Nueva España. 
La tutela imperial de los indígenas en el Segundo Imperio Mexicano (1864-1866)

La mayoría de los casos estudiados por la Junta Protectora de las Clases Menesterosas - su periodo de trabajo abarcó los últimos dos años del poder imperial 1865-1866- se centraron en los problemas de la propiedad de la tierra indígena, como fue el caso del Juzgado General de Indios de México durante la Nueva España. La adopción del modelo colonial de tutela de los indígenas se advierte, entre otras cosas, en el hecho de que los miembros de la Junta Protectora de las Clases Menesterosas utilizaron argumentos basados en el derecho indiano (Tau, 1990: 574-575), así como en las normas mexicanas, para expresar sus opiniones (Meyer, 1993: 338).

La Junta Protectora de las Clases Menesterosas complementó las audiencias semanales celebradas por el emperador, durante las cuales se recibieron oralmente las peticiones y quejas de los pueblos indígenas, por lo que no todos los casos fueron conocidos por la Junta Protectora de las Clases Menesterosas. Aunque el 26 de julio de 1865 se ordenó la creación de Juntas auxiliares en todos los municipios de los departamentos del Imperio para proponer a la Junta ubicada en la Ciudad de México medidas dirigidas a: “[...] reducir los abusos o mejorar las condiciones de los pueblos[...]"; la mayoría de las veces, los pueblos indígenas iban a la Ciudad de México en busca de la protección de la Junta Protectora de las Clases Menesterosas. Este hecho muestra la similitud de la Junta Protectora de las Clases Menesterosas con la protección paterna ejercida por el virreinato en la audiencia de la Ciudad de México a favor de los pueblos indígenas del virreinato de la Nueva España (Velásquez, 2010: 337).

Las medidas propuestas por la Junta Protectora de las Clases Menesterosas en relación con la enseñanza de las primeras letras forman parte del proyecto del emperador de educación gratuita y obligatoria para los niños de cinco años o más. Este proyecto educativo fue establecido puntualmente en la Ley No. 176 "Ley de Instrucción Pública y su Reglamento" publicada el 27 de diciembre de 1865 (Boletín de leyes del imperio mexicano, 1865). La Junta Protectora de las Clases Menesterosas propuso medidas para facilitar la implementación de la Ley de Educación Pública para que los indígenas recibieran las primeras letras. Estas propuestas dieron como resultado el establecimiento de obligaciones legales que fueron incorporadas en dos leyes, a saber, la Ley de Trabajadores Agrícolas y el Decreto de Fundo legal.

\subsubsection{La Ley de Trabajadores Agrícolas}

La Ley de Trabajadores Agrícolas subraya la obligación de los agricultores con más de veinte familias en sus granjas de establecer una escuela gratuita de primeras letras. Esta obligación se extendió a las fábricas y talleres con más de cien empleados (León Portilla, 2003b: 31-32). La misma disposición que favorece el estudio de las primeras letras se encuentra en el decreto de fundo legal publicado el 
16 de septiembre de 1866. Este decreto estableció que se instalaría una escuela de primeras letras como condición necesaria para la distribución de las tierras comunales a las aldeas de más de cuatrocientos habitantes. En estas propuestas, podemos observar que la Junta Protectora de las Clases Menesterosas estimó la educación de los pueblos indígenas en español como una medida para mejorar sus vidas e integrarlos gradualmente a la sociedad mexicana.

Asimismo, las propuestas de la Junta Protectora de las Clases Menesterosas para regular las condiciones de trabajo de las poblaciones indígenas se implementaron mediante la promulgación de la Ley sobre los trabajadores del campo. La Ley sobre los trabajadores del campo, publicada el 1 de noviembre de 1865, no implica un reconocimiento de los derechos laborales sino una medida legal con la cual el emperador Maximiliano ejerció su poder para proteger a los pueblos indígenas. Esta regulación tenía la intención de evitar las malas condiciones de trabajo que se habían practicado en las haciendas. La ley supeditaba el trabajo de los menores a la autorización de sus padres o, en su ausencia, a la autoridad civil. Podemos observar claramente la naturaleza protectora de esta ley en las siguientes medidas (León Portilla, 2003b: 30-31):

- El ajuste de la jornada laboral según el ciclo solar, con excepción de los lugares donde el sol pueda perturbar y donde el inicio de la jornada laboral sea adelantado, en cuyo caso el horario debía ser ajustado por la tarde (art. 2).

- La regulación de los días de descanso obligatorio, es decir, los domingos y los días festivos (art. 3).

- La limitación de las actividades autorizadas a los niños menores de 12 años, que sólo podían trabajar en una actividad acorde con su fuerza y sólo medio día al día (art. 4).

- La obligación de los empleadores de pagar en efectivo (art. 5).

- La prohibición de que los propietarios de explotaciones agrícolas impidan la entrada de comerciantes ambulantes para vender sus productos (art. 7).

- La obligación de los empleadores de proporcionar agua y vivienda a los trabajadores (art. 8).

- La prohibición de la existencia de prisiones y de todos los castigos corporales en las granjas (art. 9).

- La obligación del empleador de proporcionar el equipo de labranza del suelo (art. 10).

- La determinación de que las deudas del empleado deben deducirse de su salario en una quinta parte (art. 11).

- La prohibición de la transmisión de deudas de padre a hijos. Estos últimos sólo serían responsables en la medida de su herencia (art. 12). 
La tutela imperial de los indígenas en el Segundo Imperio Mexicano (1864-1866)

- La prohibición de que los padres entregaran a sus hijos a los hacendados y la correspondiente prohibición de que los propietarios aceptasen esos contratos (art. 14).

- La obligación del empleador de prestar atención médica en caso de enfermedad, si el empleado la acepta, y de deducir los gastos de su salario diario (art. 15).

El orden social doméstico de la relación entre el propietario y los trabajadores queda de manifiesto por tres disposiciones. La primera es limitar la libertad del trabajador para rescindir el contrato de trabajo sólo si paga íntegramente sus deudas (art. 1); la segunda es advertida por la utilización en la ley de la palabra "amo" para designar al propietario de la explotación agrícola (art. 15); y la tercera es la existencia de la libreta foliada, es decir, un registro en el que se registraban todos los pagos y las deudas del trabajador (art. 13).

Por otra parte, una de las prioridades de la Junta Protectora de las Clases Menesterosas fue la constitución de nuevos pueblos indígenas para lo cual propuso la Ley sobre terrenos de comunidad y de repartimiento que fue aprobada y publicada por el emperador con su traducción al náhuatl. En la Ley sobre terrenos de comunidad y de repartimiento, publicada el 26 de junio de 1866, el emperador ejerció su poder absoluto de transferir la tierra a los colonos que la ocupaban (art. 1), a menos que una persona hubiera acreditado un derecho anterior de propiedad sobre la misma tierra (art. 2) (León Portilla, 2003b: 36). Podemos observar en esta ley la intención del emperador de constituir núcleos poblacionales de ciudades en las que la propiedad privada y útil estaba incluida en el régimen comunitario. Por un lado, el aspecto favorable de la propiedad privada se refleja en la disposición (art. 3) que ordena que: "La tierra comunitaria se dividirá en fracciones y se asignará en propiedad a los vecinos [...]" (León Portilla, 2003b: 36). Y en la que se establece en el artículo 5, que señalaba: "Las tierras que los vecinos de las aldeas han destinado al culto de un santo[...] se repartirán y repartirán conforme a esta ley[...]"(León Portilla, 2003b: 36). Por otra parte, el sentido de comunidad se evalúa en la prohibición (art. 6) que dice: "Las tierras destinadas exclusivamente al servicio público de los pueblos, las aguas y las montañas, cuyos usos son realizados directamente por los vecinos de los pueblos a los que pertenecen, no serán distribuidas ni asignadas[...]" (León Portilla, 2003b: 36).

La ley establecía la obligación para todos los municipios del Imperio de establecer un registro detallado de los propietarios de las tierras, pueblos y distritos incluidos en su territorio, especificando su extensión, límites, calidad y precio, así como las familias o personas privadas de tierras y las tierras dedicadas al culto del santo patrono (artículo 7) (León Portilla, 2003b: 37). Estos registros se utilizaron para asignar tierras pertenecientes a los pueblos indígenas, que recibieron títulos individuales de su propiedad (art. 9) (León Portilla, 2003b: 37). Sin embargo, el 
derecho de propiedad se limitaba a una parcela por propietario (artículo 14) (León Portilla, 2003b: 38). Además, estaba prohibido que cada familia tuviese más de media caballería de trabajo (art. 16) (León Portilla, 2003b: 38). Esta ley establecía (art. 20) (León Portilla, 2003b: 39) que las autoridades municipales estaban obligadas a transmitir a la Junta Protectora de las Clases Menesterosas una lista de las personas que se habían beneficiado de la asignación de tierras en propiedad.

Sin embargo, las propuestas de la Junta Protectora de las Clases Menesterosas que tuvieron mayor impacto en las condiciones de vida de los pueblos indígenas son las relativas a la distribución de las tierras comunales. La exclusividad de la propiedad privada, derivada de la constitución liberal de 1857, había debilitado los cimientos de la sociedad indígena mexicana que se había apoyado en la propiedad comunal como refugio. El gobierno imperial de Maximiliano revocó esta disposición por el decreto del fundo legal.

\section{El solutio legibus y el decreto de fundo legal}

El decreto de fundo legal fue publicado el 16 de septiembre de 1866 a propuesta de la Junta Protectora de las Clases Menesterosas. El decreto de fundo legal fue la decisión más protectora otorgada a la propiedad comunal indígena durante el Segundo Imperio Mexicano. Su propósito era proporcionar tierras a los pueblos indígenas. El decreto del fundo legal es un ejemplo de cómo el emperador Maximiliano regresó a un orden social doméstico similar al que existía bajo el dominio castellano en la Nueva España. El fundo legal (Universidad de Michigan, 14-05-2019) tiene su origen en la legislación vigente en la Nueva España. El rey Felipe IV en las ordenanzas dictadas en Madrid el 16 de marzo de 1642 y en Zaragoza el 30 de junio de 1646 y recogidas como Ley XVIII, Libro IV, Título XII de la Recopilación de Leyes de Indias ordenó que en la venta, aprovechamiento y composición de las tierras: “[...] los indios se quedan con más que suficiente de ellos les pertenecen, en particular, como por las comunidades, y las aguas y las irrigaciones; y las tierras en las que habían hecho zanjas, o cualquier otro beneficio [...] y por ninguna razón pueden ser vendidos, o enajenados [...]" (Recopilación de Leyes, 1841).

La tierra concedida por el emperador en su poder absoluto tenía la característica de ser útil y productiva (art. 2) (León Portilla, 2003b: 25). Se estableció que las aldeas con más de dos mil habitantes también tenían derecho a tierras cultivables, cuya extensión se determinó caso por caso, según las condiciones de cada población (art. 3) (León Portilla, 2003b: 25). Cuando se alcanzó el número de dos mil o más habitantes, el gobierno les dio mejores condiciones para formar grandes centros de población (art. 6) (León Portilla, 2003b: 25). En el caso de las aldeas que no tenían el número necesario de habitantes se les permitía unirse a otras poblaciones para formar una unidad de población. En este caso, los habitantes que 
La tutela imperial de los indígenas en el Segundo Imperio Mexicano (1864-1866)

se trasladaron a otra aldea fueron compensados sobre la base del valor de la tierra que dejaron (art. 4) (León Portilla, 2003b: 25). Las tierras asignadas a las aldeas correspondían a tierras baldías o, en algunos casos, fueron adquiridas por el gobierno mediante la compra a sus propietarios. En caso necesario, los terrenos fueron expropiados tras la indemnización de los antiguos propietarios (art. 9) (León Portilla, 2003b: 25).

La política de colonización bajo el Segundo Imperio Mexicano se basó en tres principios, a saber, el uso de tierras privadas, el intento de crear asentamientos y el perfil de los colonos deseados. El principal interés de la Junta Protectora de las Clases Menesterosas era que la colonización no afectara las propiedades comunales de los pueblos indígenas. Esto es lo que se desprende claramente de la propuesta de la circular acerca de que el desarrollo de la colonización de terrenos baldíos no se extienda a los terrenos comunales publicada el 14 de septiembre de 1865. La circular garantiza a los pueblos indígenas la máxima protección del derecho a la propiedad de sus tierras comunales. Así lo advertimos de la orden para que en el desarrollo de la colonización de las tierras baldías: “[....] no se vean afectadas las propiedades de los pueblos[...]" (León Portilla, 2003b: 29-30). Esta circular establece una garantía legal que protege las tierras comunales y las clasifica como lugares que no pueden ser afectados por el desarrollo colonizador. A este respecto, destacamos que las medidas para el desarrollo de nuevos núcleos de población: “[...] no se extienden a las tierras comunales, ni deben incluirse en los informes de terrenos baldíos [...]"(León Portilla, 2003b: 30). Esto nos muestra que la propiedad comunal tenía un valor predominante en el Segundo Imperio Mexicano.

El emperador ordenó que, con respecto a las tierras comunales, se tomaran todas las medidas necesarias para "[...] garantizar la propiedad de las mismas [...]"(León Portilla, 2003b: 30). Y afirmó expresamente su compromiso con los pueblos indígenas de que no se les perturbara su derecho a la propiedad de sus tierras. En este sentido, la circular afirma que: "Los pueblos pueden mantener la calma en este sentido y depositar la mayor confianza en los objetivos caritativos del Emperador" (León Portilla, 2003b: 30).

La protección de la propiedad comunal por parte del Segundo Imperio Mexicano nos recuerda la orden del Rey Felipe II dada en Madrid el 11 de junio de 1594 y compilada como Ley IX, Libro IV, Título XII de la Recopilación de Leyes de Indias, (1841) para evitar que la distribución de tierras a los españoles durante la Nueva España cause daño a los pueblos indígenas. 


\section{La iurisdictio imperial y las leyes como medio para resolver los conflictos por la tierra y el agua}

En el Segundo Imperio Mexicano, el emperador era el gobernante absoluto (Estatuto Provisional del Imperio, 1865). En materia jurisdiccional, la soberanía del emperador se ejerció a través de las autoridades designadas por él. En cuanto a la resolución de los conflictos por la tierra y el agua, podemos distinguir dos etapas bajo el gobierno imperial. La primera fase, que abarca el período comprendido entre el 1 de noviembre de 1865 y el 16 de septiembre de 1866 consistió en delegar en las autoridades administrativas la integración y la toma de decisiones de los casos derivados de los conflictos por tierras y aguas entre los pueblos indígenas, así como la decisión y la autorización de los pueblos indígenas para llevar los casos ante los tribunales cuando los conflictos afecten a los intereses de una persona particular.

La segunda fase correspondió a la resolución de este tipo de conflictos por parte del juez ordinario. Es importante señalar que esta distinción es el resultado de un proceso de protección de los pueblos indígenas que se llevó a cabo durante el último período del gobierno imperial, a partir del 16 de septiembre de 1866, para promover la autonomía de los pueblos indígenas. Sin embargo, apreciamos que la protección paterna expresada en las leyes de la lengua náhuatl no desapareció completamente.

\subsection{Las facultades de los consejos departamentales para resolver las disputas sobre tierras y aguas}

La Ley para dirimir las diferencias sobre tierras y aguas entre los pueblos publicada el 1 de noviembre de 1865 establece un procedimiento por el cual la autoridad administrativa, a saber, los prefectos y los consejos departamentales actúan como intermediarios en los conflictos por la tierra o el agua que surgían entre los pueblos y los individuos, o entre los propios pueblos.

En el caso de los conflictos por la tierra y el agua, se preveía que los pueblos o los demandantes privados tendrían que preparar un expediente que integrara sus reclamaciones y documentos en apoyo del derecho reivindicado (art. 1) (León Portilla, 2003b: 32-33). Este expediente se entregaba a los prefectos de cada departamento en el que se encontraba el terreno o el agua. El prefecto de la administración imperial era el representante designado por el emperador para gobernar los departamentos (Estatuto Provisional del Imperio, 1865). El prefecto era responsable de gobernar el territorio de su circunscripción y de ejercer las facultades que las leyes le indicaban explícitamente. Subordinada a los prefectos, la organización imperial preveía la existencia de municipios en el ámbito local con sede en cada ciudad y teniendo como máxima autoridad al alcalde que tenía poderes limitados a las actividades municipales y podía ser destituido a voluntad del prefecto 
en el ámbito de su competencia y del emperador. En el caso de los conflictos por la tierra y el agua entre los pueblos indígenas entre sí y entre pueblos e individuos, los alcaldes fueron los representantes de los pueblos indígenas en las actuaciones. Además, dependiendo de las condiciones de la municipalidad, era posible nombrar abogados para que asesoraran al alcalde. De esta manera, podemos ver que el gobierno imperial estableció una estructura organizativa que penetró en todos los niveles del poder público, llegando al nivel local para garantizar los derechos de los pueblos indígenas, especialmente en lo que se refiere a la propiedad de la tierra y el agua. El emperador también prestó especial atención al hecho de que los pueblos indígenas estuviesen debidamente representados en el ámbito jurídico para que sus derechos fueran respetados.

El procedimiento previsto en la Ley para dirimir las diferencias sobre tierras y aguas entre los pueblos consiste en que, una vez elaborado el expediente, el prefecto lo daba a conocer al demandado, ya sea un particular u otra población, para que éste pudiese formular las alegaciones de las que tuviera conocimiento y adjuntara, en su caso, los documentos correspondientes para acreditar su derecho (art. 2) (León Portilla, 2003b: 33). En caso de que los demandados no respondieran, se declaraba su desinterés y, sin juicio previo, el Ministerio Público tomaba las medidas necesarias para que los demandantes hubieran garantizado sus derechos sobre la tierra o el agua en cuestión (art. 3) (León Portilla, 2003b: 33). Además, se preveía una sanción para las partes que no preparasen adecuadamente su expediente, ya que los documentos que no se hubieran presentado al prefecto no podrían ser presentados al juez (art. 4) (León Portilla, 2003b: 33). Una vez integrado el expediente correspondiente, el conflicto se sometía al consejo departamental para su resolución.

La competencia del Consejo Departamental para resolver disputas sobre tierras y aguas fue establecida por el artículo 30, párrafo III, del Estatuto Provisional del Imperio que preveía como una de las facultades de este órgano administrativo la de dar: "III. Audiencia de casos contencioso-administrativos en virtud de la ley disponible [...]”(León Portilla, 2003b: 33). En la fracción II del mismo artículo 30 del Estatuto Provisional del Imperio, la función de protección confiada al Consejo Departamental respecto de los pueblos indígenas estaba claramente indicada como una de sus competencias: "II. Promover formas de reducir los abusos o mejorar la situación de los pueblos[...]” (León Portilla, 2003b: 33).

La competencia del Consejo Departamental en esta materia estaba ligada al poder otorgado a la Junta Protectora de las Clases Menesterosas para proponer al Emperador la forma en que los casos de las clases menesterosas podrían ser resueltos ante los tribunales. Estos dos órganos eran los receptores de los conflictos territoriales de los pueblos indígenas y, en el caso del consejo departamental, también era responsable de atender los casos de problemas que pudieran afectar los derechos de las personas frente a los pueblos indígenas. El objetivo de este sistema 
de doble filtro era que el Emperador se asegurara de que las cuestiones relativas a la tierra y el agua de los pueblos indígenas estuvieran debidamente documentadas y resueltas por los tribunales, en los que el Emperador pudiera ejercer su poder como primer magistrado.

El consejo departamental de cada región resolvió los conflictos por la tierra y el agua entre los pueblos indígenas entre sí o entre los pueblos indígenas y las personas. La resolución del consejo departamental tenía dos posibilidades (art. 6) (León Portilla, 2003b: 33-34). Por un lado, si la disputa era entre pueblos, se decidía quién tenía el mejor derecho de posesión, pero en ningún caso se les permitía llevar su caso ante los tribunales. En otras palabras, las disputas entre los pueblos no eran responsabilidad de los jueces, sino de los consejos departamentales. Por otra parte, si el conflicto se refería a los intereses de un pueblo y de un individuo, la decisión del consejo departamental debía tener en cuenta el carácter procesal de los pueblos indígenas, es decir, en el caso de que los pueblos fuesen denunciantes contra individuos, la decisión autorizaba el enjuiciamiento del caso si los expedientes demostraban que existían pruebas suficientes para solicitar justicia. En este caso, los consejos departamentales designaban abogados para que defendieran a los pueblos y los representasen ante los tribunales. Si no había pruebas convincentes para argumentar la causa de la justicia, a la gente se le negaba este poder. En el caso de las pueblos fueran los acusados, se les permitía demandar cuando se les advertía que tenían mejores derechos que las personas que los demandaban y también se les designaba abogados defensores para representarlos. En caso de desacuerdo con la resolución del consejo departamental y siempre que el valor del terreno o del agua superase los cien pesos, el pueblo podía solicitar su revisión ante la Secretaría de Gobernación, que era quien finalmente decidía (art. 7) (León Portilla, 2003b: 34). Las personas tenían el mismo derecho a solicitar una revisión ante el Ministerio del Interior, pero si lo hacían, renunciaban a los procedimientos judiciales (art. 8) (León Portilla, 2003b: 34).

Por lo tanto, vemos que esta ley tenía un carácter protector para los pueblos indígenas a fin de garantizar sus derechos a la propiedad de la tierra y el agua. Esta protección implicaba su protección por parte de las autoridades administrativas, que permitía a las personas comparecer ante los tribunales, ya sea como demandantes o como demandados si era necesario, y garantizar su representación legal, mediante el nombramiento de abogados para defenderlos.

\subsection{Los procedimientos judiciales para la solución de las controversias relativas a la tierra y al agua}

La segunda etapa — a partir del 16 de septiembre de 1866 - de la evolución del modelo de resolución de conflictos por la tierra y el agua en el Segundo Imperio Mexicano implicó la intención del emperador de conceder autonomía a los pueblos 
La tutela imperial de los indígenas en el Segundo Imperio Mexicano (1864-1866)

indígenas para que pudieran recurrir directamente a los tribunales sin pasar por el proceso administrativo. Observamos en este período el ejercicio de la simple jurisdicción de los tribunales locales que, según la delegación que el emperador les había hecho, eran los encargados de resolver los casos que se les presentaban.

El emperador Maximiliano promulgó dos normas que implicaban el acceso directo de los pueblos indígenas, individual o colectivamente, a la jurisdicción ordinaria. La primera de estas disposiciones legales fue el decreto sobre demandas de daños y perjuicios causados por animales en pastos y sembradíos. La segunda ley fue la que resolvió los conflictos por el agua y la tierra, de los que hablaremos más adelante. Estos conflictos fueron sometidos a los jueces que ejercían la justicia en nombre del emperador.

\subsubsection{El decreto sobre demandas de daños $\mathrm{y}$ perjuicios causados por animales en pastos y sembradíos}

El artículo 1 del Decreto sobre demandas de daños y perjuicios causados por animales en pastos y sembradíos establecía que: "Las reclamaciones de indemnización por daños causados por animales a los pastos de cualquier explotación agrícola deberán presentarse ante la autoridad judicial competente" (León Portilla, 2003b: 35). Aunque el decreto sobre demandas de daños y perjuicios causados por animales en pastos y sembradíos, publicado el 25 de junio de 1866, no estaba dirigido específicamente a las poblaciones indígenas, el hecho es que se aplicaba a muchas personas que vivían en el campo. Observamos que no hay calificación de los sujetos, pero la intención era proteger los terrenos que habían sido dañados.

El objetivo de este decreto es garantizar la indemnización de los daños causados por la presencia de animales en pastos o campos. El nexo causal entre el hecho y el daño causado tenía que ser probado en los tribunales y luego cuantificado por expertos para poder reparar el daño. Se prohibía explícitamente a las personas que tomaran sus propias medidas para hacer valer sus derechos. La única excepción a esta prohibición era la posibilidad de que los perjudicados mantuvieran a los animales causantes de los daños durante un máximo de doce horas, tras lo cual debían presentarlos al juez con la advertencia de que si no lo hacían o si maltrataban a los animales detenidos, perderían el derecho a la indemnización correspondiente y tendrían que pagar una multa.

En el artículo 7 se preveía una pena más severa para toda persona que hubiera pastado malintencionadamente sus animales en tierras ajenas, en cuyo caso se duplicaba el importe de la indemnización, además de imponerse una multa de cincuenta céntimos al responsable por cada cabeza de animal que hubiera causado los daños. Del mismo modo, la reincidencia se consideraba un acto intencionado 
por parte del responsable, que era responsable de la misma duplicación del importe de la indemnización y de la multa correspondiente.

La justicia así ejercida por los tribunales era de carácter público y pacífico. Su objetivo era resolver los conflictos dentro de un marco jurídico claro y objetivo. De acuerdo con la intención del emperador de otorgar mayor autonomía a los pueblos indígenas para que pudieran ser incorporados a la vida pública, el decreto de fundo legal, emitido el 16 de septiembre de 1866, determinó que los conflictos por la tierra y el agua se resolvían ante los tribunales ordinarios.

\subsubsection{La ley sobre la resolución de los conflictos por el agua y la tierra}

La resolución de los conflictos por el agua y la tierra a través de los tribunales abarcaba todos los casos posibles, es decir, incluía tanto los conflictos relacionados con la tierra y el agua entre los pueblos como los conflictos entre pueblos e individuos indígenas. También incluía todos los derechos sobre la tierra y el agua derivados tanto de la posesión como de la propiedad. Subrayamos la prioridad que el emperador dio a la resolución de este tipo de conflictos para restaurar el orden en su imperio cuando decidió que sería un juicio sumario que se resolvería lo antes posible e incluso con la posibilidad de reducir sus plazos. Esta reducción de los plazos estaba sujeta al respeto del derecho de la defensa a presentar pruebas. En otras palabras, los plazos no podrían acortarse si no se hubieran agotado todas las pruebas presentadas por las partes.

El mismo interés imperial para que estos conflictos se resolvieran rápidamente se observa en la disposición legal que establecía la prescripción de acción en tres años para exigir los derechos de posesión y propiedad de la tierra y el agua. Este período se contaría a partir de la publicación del decreto, es decir, el último plazo previsto para comparecer ante los tribunales para hacer valer sus derechos sería el 16 de septiembre de 1869; sin embargo, el gobierno imperial fue derrotado en 1867.

También valoramos la prioridad que el emperador Maximiliano dio a este tipo de conflicto en la disposición que prohíbe la renuncia a los procedimientos en relación con estos conflictos. A este respecto, se dispuso que los litigantes no podían abandonar el procedimiento y que, en caso afirmativo, debía designarse a un defensor para que continuara el procedimiento a expensas de los abogados que se habían retirado. En otras palabras, el emperador no quería que ningún conflicto sobre la tierra y el agua se quedara sin resolver.

Si bien es cierto que el significado general de estas disposiciones era permitir el acceso directo de los pueblos indígenas a la jurisdicción ordinaria, también es cierto que la protección paterna del emperador no desapareció completamente en este decreto. Esto se refleja en la disposición legal que ordena que los pueblos indígenas estuvieran representados legalmente en los juicios por los respectivos alcaldes o comisionados imperiales, y en caso de que fueran rechazados u obstaculizados, los 
La tutela imperial de los indígenas en el Segundo Imperio Mexicano (1864-1866)

pueblos podían designar a cualquier persona como su representante legal, siempre y cuando contaran con la autorización de las autoridades civiles del distrito correspondiente (art. 13) (León Portilla, 2003b: 35). Así como en la disposición que establecía que los pueblos conservaban su derecho a quejarse ante el emperador, a través de la Junta Protectora de las Clases Menesterosas, de la negativa injustificada de las autoridades municipales a representarlos ante los tribunales (art. 14) (León Portilla, 2003b: 35).

La misma ley imponía sanciones a quienes violaran las normas para resolver estos conflictos con el fin de obtener un beneficio personal. A este respecto, la ley preveía la posibilidad de castigar a toda persona que, sin tener una condición jurídica reconocida, compareciera ante los tribunales para defender a los pueblos indígenas (art. 15) (León Portilla, 2003b: 35). También se preveían sanciones para las autoridades políticas y judiciales que, sin fundamento jurídico, intentaran exigir cualquier derecho a la posesión y propiedad de las tierras y aguas en litigio; en tales casos, se preveía la destitución de esas autoridades (art. 16) (León Portilla, 2003b: 35).

Este sistema de acceso directo de los pueblos indígenas a la justicia ordinaria derogó el método de intervención de las autoridades administrativas previsto por la ley para resolver los conflictos de tierras y aguas entre los pueblos, que ya hemos mencionado. Así pues, todas las cuestiones pendientes de resolución y posteriores a la fecha de publicación del decreto del fundo legal, es decir, a partir del 16 de septiembre de 1866, se resolverían por vía judicial (art. 18) (León Portilla, 2003b: 35).

\section{Conclusión}

La tutela durante el Segundo Imperio Mexicano fue utilizada por el emperador Maximiliano para gobernar a los pueblos indígenas en un orden social doméstico similar al establecido en el virreinato de la Nueva España, en el que el soberano ejercía las dimensiones paterna, jurisdiccional y absoluta de su poder.

Como padre, el emperador utilizó las leyes para proteger a los indígenas, mediante su clasificación dentro de las clases menesterosas. Esto le permitió al emperador estructurar una política de tutela hacia los indígenas, tanto individual como colectivamente. La pretensión del emperador era integrar a los indígenas paulatinamente a la sociedad de donde habían sido históricamente aislados.

Como autoridad con poder absoluto, el emperador Maximiliano dictó leyes para dotar a los pueblos indígenas de tierras útiles y suficientes. A este respecto, destaca la reintroducción de la propiedad comunal, la cual había sido desplazada por la propiedad privada en la constitución mexicana de 1857.

Como autoridad jurisdiccional suprema, el emperador utilizó las leyes para garantizar que se hiciera justicia a los pueblos indígenas a causa de los conflictos por la tierra y el agua. En este sentido, aunque el emperador tuvo la intención de 
dotar de autonomía a los indígenas para que ejercieran por sí mismos sus derechos, particularmente en los últimos dos años del poder imperial, lo cierto es que la protección imperial hacia los indígenas nunca desapareció.

\section{Referencias bibliográficas}

Boletin de las leyes del imperio mexicano: Comprende las leyes, decretos y reglamentos generales, numeros del 1 al 176, expedidos por el Emperador Maximiliano desde 1o. de julio hasta 31 de diciembre de 1865. Universidad Autónoma de Nuevo León. Asequible en: https://cd.dgb.uanl.mx/handle/201504211/15705, fecha de consulta: 14-05-2019.

Boletín de las leyes del imperio mexicano ó sea Código de la Restauración. Colección completa de las leyes y demás disposiciones dictadas por la intervención francesa, por el Supremo Poder Ejecutivo Provisional, y por el Imperio Mexicano, con un apéndice de los documentos oficiales más notables y curiosos de la época (1863). México. Publicado por José Sebastián Segura, Imprenta Literaria, 4 Tomos. Asequible en: https://catalog.hathitrust.org/Record /001625516, fecha de consulta: 27-05-2019.

Busaall, Jean-Baptiste (2014). Les Indes espagnoles, 1492-1837, une colonisation sans colonies. En: Gojosso, Éric - Kremer, David - Vergne, Arnaud (dir.). Les colonies. Approches juridiques et institutionnelles de la colonisation de la Rome antique à nos jours. Poitiers: LGDJ-Press universitaires juridiques de Poitiers, Faculté de Droit et des Sciences Sociales de Poitiers. 143-172.

Constitución Federal de los Estados Unidos Mexicanos, sancionada y jurada por el Congreso general constituyente el día cinco de febrero de 1857. Orden Jurídico. Gobierno de México. Asequible en: http://www.ordenjuridico.gob.mx/Constitucion/1857.pdf, fecha de consulta: 09-05-2019.

Dios de Dios de, Salustiano (s.f.). Gregorio López. En: Real Academia de la Historia. Diccionario Biográfico Elestrónico. Asequible en: http://dbe.rah.es/biografias /15890 /gregorio-lopez, fecha de consulta: 10-05-2019.

Duchesne, Albert (1968). Édouard-Joseph Felix Eloin. En: Royal Academy of Overseas Sciences, Belgian Overseas Biography. T.VI Col. 356-358. Asequible en: https://www.kaowarsom.be/en/notices_eloin_edouard_joseph_felix, fecha de consulta: 12-05-2019.

Estatuto Provisional del Imperio, Universidad Nacional Autónoma de México. Asequible en: http://museodelasconstituciones.unam.mx/nuevaweb/wp-content/uploads/2019/ 02/Estatuto-provisional-del-Imperio-Mexicano-1865-.pdf, fecha de consulta: 0905-2019.

Jancsó, Katalin (2009). El indigenismo de Maximiliano en México (1864-1867). Acta Hispanica. 14. Asequible en: http://acta.bibl.u-szeged.hu/630/1/hisp_014_005018.pdf, fecha de consulta: 11-05-2019. 
La tutela imperial de los indígenas en el Segundo Imperio Mexicano (1864-1866)

León Portilla, Miguel (2003a). Obras de Miguel León-Portilla, Tomo I. Pueblos indígenas de México. Autonomía y Diferencia Cultural. México, D.F.: Universidad Nacional Autónoma de México, El Colegio Nacional.

León Portilla, Miguel (2003b). Ordenanzas de tema indígena en castellano y nábuatl, edición facsimiliar de Querétaro. Querétaro, México: Instituto de Estudios Constitucionales de Querétaro.

Marino, Daniela (2006). Ahora Que Dios Nos Ha Dado Padre [...] El Segundo Imperio y la cultura jurídico-política campesina en el centro de México. Historia Mexicana, vol. 55, no. 4. 1353-1410. Asequible en: www.jstor.org/ stable /25139687, fecha de consulta: 14-05-2019.

Maximiliano, Emperador de México (2014). Recuerdos de mi vida, Memorias de Maximiliano, Trad. don José Linares y don Luis Méndez, Imprenta de I. Escalante y Ca. Tomo Segundo (1869). Alicante: Biblioteca Virtual Miguel de Cervantes. Asequible en: http://www.cervantesvirtual.com/obra/recuerdos-de-mi-vida-memorias-demaximiliano-tomo-segundo/, fecha de consulta: 12-05-2019.

Meyer, Jean (1993). La junta protectora de las clases menesterosas. Indigenismo y agrarismo en el Segundo Imperio. En: Escobar Ohmstede, Antonio. Indio, nación y comunidad en el México del siglo XIX. México, D.F.: Centro de Estudios Mexicanos y Centroamericanos/Centro de Investigaciones y Estudios Superiores en Antropología Social. 329-364.

Ministerio de Cultura y Deporte, Gobierno de España (s.f.). Consejo de Indias. Bicentenario de las Independencias Iberoamericanas. Asequible en: http://pares.mcu.es/ Bicentenarios/portal/consejoDeIndias.html, fecha de consulta: 07-05-2019.

Ordenanzas Reales de Castilla. Biblioteca digital de la Junta de Castilla y León. Asequible en: https://bibliotecadigital.jcyl.es/i18n/catalogo_imagenes/grupo.cmd?path=10120030, fecha de consulta: 06-05-2019.

Pani, Erika (1998). ¿"Verdaderas figuras de Cooper" o "pobres inditos infelices"? La política indigenista de Maximiliano. Historia Mexicana, vol. 47, no. 3. 571-604. México, D.F.: El Colegio de México. Asequible en: https://historiamexicana.colmex.mx /index.php/RHM/article/view/2410/2815, fecha de consulta: 15-12-2020.

Ramírez Bañuelos, Jesús Francisco (2020). La (des)autorización del uso de la lengua náhuatl en la legislación de la Nueva España. Revista Jurídica Jalisciense. Año XXX, núm. 63, julio-diciembre de 2020. Universidad de Guadalajara.

Ratz, Konrad (1998). Maximilian y Juárez. El Segundo Imperio Mexicano y la República. Backgrounds, documents and eyewitness accounts, vol. I, Graz, Austria.

Recopilación de Leyes de los reinos de las Indias mandadas imprimir y publicar por la Magestad Católica del Rey Don Carlos II. Nuestro Señor. Va dividida en Cuatro Tomos, con el índice general, y al principio de cada Tomo el especial de los títulos que contiene. Tomo Segundo. Quinta Edición con aprobación de la Regencia Provisional del Reino 
corregida y aprobada por la Sala de Indias del Tribunal Supremo de Justicia (1841). Madrid: Boix Editor. Asequible en: http://www.cervantesvirtual.com/research / recopilacion-de-leyes-de-los-reinos-de-indias-mandadas-imprimir-y-publicar-por-lamagestad-catolica-don-carlos-ii-tomos-2-777027/b808338a-8b0a-40e4-9444f52ae70a0748.pdf, fecha de consulta: 06-05-2019.

Solórzano Pereira, Juan (de) (1703). Politica indiana, compuesta por D. Juan de Solórzano Pereira, dividida en seis libros, en los quales se trata y resuelve todo lo tocante al descubrimiento, descripción, adquisición y retención de las mesmas Indias. Amberes: H. y C. Verdussen.

Tau Anzoátegui, Victor (1990). El derecho indiano en su relación con los derechos castellano y común. En: Clavero, Bartolomé - Grossi, Paolo - Tomás y Valiente, Francisco (eds.): Hispania. Entre derechos propios y derechos nacionales. Atti dell'incontro di studio. Firenze-Lucca 25, 26, 27 Maggio 1989, Tomo II. Milano: Giuffrè Editore, Centro di Studi per la storia del pensiero giuridco moderno 34/35. 573-592.

Universidad de Michigan (s.f.). Asequible en: https://umich.edu/search/?keywords $=$ media + caballer $\%$ C3\%ADa, fecha de consulta: 14-05-2019.

Vallejo Fernández de la Reguera, Jesús (2012). El príncipe ante el derecho en la cultura del Ius Commune. En: Lorento, Marta - Vallejo, Jesús (Coord.). Manual De Historia Del Derecho. Valencia : Tirant Lo Blanch. 141-178.

Velásquez García, Erik et al. (2010). Historia general de México, México, D.F.: El Colegio de México. 